\title{
PEMBANGUNAN DESTINASI PARIWISATA YANG BEKELANJUTAN MELALUI PENERAPAN NILAI-NILAI ERGONOMI
}

\author{
Ni Made Eka Mahadewi ${ }^{1 *}$, Ni Ketut Dewi Irwanti² \\ 1,Magister Terapan Pariwisata, Politeknik Pariwisata Bali \\ Jl. Dharmawangsa Kampial, Nusa Dua Bali \\ 2Universitas Triatmamulya, \\ Jl. Kubu Gn., Dalung, Kec. Kuta Utara, Kabupaten Badung, Bali \\ ${ }^{1 *}$ eka.mahadewi@gmail.comi,2nk_dewi_irwanti@yahoo.com \\ ${ }^{*}$ Corresponding Author
}

\begin{abstract}
The development of tourism can not only refer to attractions, accessibility and destination facilities. However, the values of structuring in each tourist attraction in a destination are important to note. And along with various tourism developments, the comfort factor is one of the important factors that determine the decision of tourists to visit a tourist destination. Many things affect the comfort of tourists while in a tourist destination. One of the approaches used to make tourists comfortable using the infrastructure, facilities, tourist activities, and services provided is to implement the ergonomic approach that seeks for people to be healthy, safe, comfortable, effective and efficient so that they are more productive and the quality of life is better also they got happiness and sustainable.
\end{abstract}

Keywords: comfortable, tourist destination, ergonomic, sustainable tourism

\begin{abstract}
Abstrak
Perkembangan pariwisata tidak sepenuhnya hanya dapat mengacu pada atraksi, aksesibilitas dan fasilitas destinasi. Namun nilai-nilai penataan dalam setiap daya tarikwisata di destinasi, menjadi penting untuk diperhatikan. Dan seiring dengan berbagai perkembangan pariwisata tersebut, faktor kenyamanan menjadi salah satu faktor penting yang menentukan keputusan wisatawan untuk berkunjung ke suatu destinasi wisata. Banyak hal yang mempengaruhi kenyamanan wisatawan selama ada di destinasi wisata. Salah satu pendekatan yang digunakan untuk membuat wisatawan nyaman menggunakan sarana prasarana, fasilitas, aktivitas wisata, maupun pelayanan yang diberikan adalah dengan menggunakan pendekatan ergonomis yang mengupayakan manusia beraktivitas secara sehat, aman, nyaman, efektif dan efisien sehingga lebih produktif dan kualitas hidup menjadi lebih baik, bahagia dan berkelanjutan.
\end{abstract}

Kata Kunci: kenyamanan, destinasi wisata, ergonomic, pariwisata berkelanjutan 


\section{PENDAHULUAN}

Daerah tujuan pariwisata atau disebut Destinasi Pariwisata adalah daerah atau kawasan yang di dalamnya terdapat daya tarik wisata, fasilitas umum, fasilitas pariwisata, aksesibilitas serta masyarakat yang terkait dan saling melengkapi terwujudnya kepariwisataan (Permenpar, 2018). Fasilitas yang disediakan antara lain, sarana prasarana, fasilitas transportasi, akomodasi, biro perjalanan, atraksi, pelayanan makananminuman, dan produk cinderamata. Khusus untuk sarana prasarana standar penyediaannya tertuang dalam peraturan Menteri Pariwisata Republik Indonesia No 3 tahun 2018 yang bertujuan untuk memenuhi kenyamanan dan keamanan wisatawan selama berwisata.

Keamanan dan kenyamanan bagi wisatawan merupakan salah satu faktor yang dapat menentukan keputusan wisatawan untuk melakukan kunjungan ke suatu objek wisata (Khalik 2014). Rasa aman dan nyaman yang dirasakan wisatawan merupakan bentuk reputasi pelayanan keamanan dan kenyamanan yang diberikan oleh daerah wisata yang berdampak pada meningkatnya confidence wisatawan untuk mengunjungi daerah wisata. Banyak pendekatan yang dapat dilakukan agar kebutuhan akan rasa nyaman dan aman terpenuhi, salah satunya dengan pendekatan ergonomic yang memegang peranan penting untuk memperoleh rasa nyaman, aman, sehat, efektif dan efisien dalam melakukan setiap aktivitas termasuk aktivitas di destinasi wisata. Penelitian ini bertujuan untuk mengetahui gambaran tentang destinasi wisata ergonomis.

\section{METODE PENELITIAN}

Dalam mennetukan hasil penelitian yang dituangkan kedalam karya bentuk artikel ini merupakan penelitian deskresearch dengan mengunakan data sekunder yang merupakan hasil dari kajian pustaka yang bersumber dari buku literatur dan berbagai hasil penelitian yang dipublikasikan baik melalui jurnal, prosiding atau sarana publikasi lainnya. Salah satu karya yang dibuat adalah artikel ini. Kajian dilakukan dengan pendekatan kajian akademis dari persepketif pariwisata yang berkelanjutan; secara komprehensif dari berbagai aspek sehingga mampu memberikan gambaran tentang destinasi ergonomis bagi wisatawan. Tujuan dari penelitian yang dilakukan adalah untuk memberikan gambaran pentingnya penerapan nilai-nilai ergonomis dalam pembangunan pariwisata; khususnya pembangunan infrastruktur pariwisata agar dapat memberikan kualitas hidup manusia menjadi lebih baik, bahagia dan berkelanjutan.

\section{HASIL DAN PEMBAHASAN \\ 3.1 Ergonomi dalam design sarana prasarana dan fasilitas destinasi wisata}

Ergonomi merupakan salah satu bidang ilmu multidisiplin yang mengkaji aktivitas manusia beserta lingkungannya dengan prinsip fitting the job to the person (Grandjean dan Kroemer, 2000). Secara definisi, ergonomi berarti hukum kerja, dimana ergos berarti kerja dan nomos berarti norma atau hukum. Secara luas Ergonomi adalah Ilmu, teknologi dan seni yang berupaya menserasikan alat, cara dan lingkungan kerja terhadap kemampuan, kebolehan dan keterbatasan manusia baik secara fisik dan mental untuk terwujudnya kondisi lingkungan kerja yang sehat, aman, nyaman efektif dan efisien demi tercapainya produktivitas yang setinggitingginya dan kualitas hidup yang lebih baik (Manuaba, 2003a; Tarwaka, 2010). Dalam perkembangannya, kata "kerja" dimaknai sebagai segala bentuk aktivitas manusia. Sehingga ergonomic mengupayakan manusia beraktivitas secara sehat, aman, nyaman, efektif dan efisien sehingga lebih produktif dan kualitas hidup menjadi lebih baik.

Aspek keamanan dan kenyamanan di destinasi wisata perlu diperhatikan, 
tidak hanya bagi wisatawan tetapi juga bagi pengelola bahkan seluruh stakeholder pariwisata. Kondisi aman yang adalah terhindar dari risiko celaka sedangkan nyaman memberi makna terpenuhinya kebutuhan fisik dan psikis seseorang berdasarkan persepsi masingmasing individu. Kondisi aman dan nyaman merupakan bagian dari kajian ergonomic yang mempertimbangkan aspek fisik, kognitif, dan lingkungan.

Beberapa hal yang perlu diperhatikan dalam menunjang aspek keamanan dan kenyamanan di destinasi wisata adalah sarana prasarana dan fasilitas. Pada umumnya fasilitas destinasi wisata belum memiliki standar ergonomis yang mengacu pada teknologi tepat guna (a) Ekonomis, teknologi yang digunakan harus memperhitungkan keuntungan yang akan diperoleh, b) teknis, teknologi yang dipilih tidak banyak menyerap energi, c) ergonomis, teknologi bermanfaat dan tidak memberi dampak negatif terhadap kesehatan fisik dan metal, d) sosio culture, kebutuhan wisatawan disesuaikan dengan budaya dan nilai-nilai estetika, e) hemat energi, penggunaan energi yang berlebihan dapat merusak tatanan yang sudah ada, f) tidak merusak lingkungan, teknologi yang digunakan tidak memberikan dampak negatif terhadap lingkungan. Standar ergonomic yang mengacu pada teknologi tepat guna dapat dijadikan dasar membangun fasilitas untuk menumbuhkan rasa aman dan nyaman bagi wisatawan.

Pembangunan sarana dan prasarana serta fasilitas penunjang di destinasi wisata sudah memiliki memiliki standar acuan tetapi belum diimplementasikan secara menyeluruh. Standar pengadaan sarana prasarana dan fasilitas penunjang tertuang dalam peraturan menteri pariwisata no 3 tahun 2018 tentang Dana Alokasi Khusus pembangunan fisik bidang pariwisata. Dalam peraturan ini disebutkan ketentuan-ketentuan pembangunan Fasilitas Pariwisata yang meliputi Pengembangan Daya Tarik Wisata dan Peningkatan Amenitas
Pariwisata. Pengembangan daya Tarik wisata antara lain; pembangunan TIC (tourist information centre); 2. Pembuatan ruang ganti dan/atau toilet; 3. Pembuatan pergola; 4. Pembuatan gazebo; 5. Pemasangan lampu taman; 6. Pembuatan pagar pembatas; 7. Pembangunan panggung kesenian/pertunjukan; 8. Pembangunan kios cenderamata; 9. Pembangunan plaza / pusat jajanan kuliner; 10. Pembangunan tempat ibadah; 11. Pembangunan menara pandang (viewing deck); 12 . Pembangunan gapura identitas; 13. Pembuatan jalur pejalan kaki (pedestrian)/jalan setapak/jalan dalam kawasan, boardwalk, dan tempat parkir; dan 14. Pembuatan rambu-rambu petunjuk arah. Sedangkan peningkatan amenitas pariwisata meliputi; 1. Pembangunan dermaga wisata; 2 . Pembangunan titik labuh / singgah kapal yacht; 3 . Pembangunan dive center dan peralatannya; 4. Pembangunan surfing center dan peralatannya; 5. Pembangunan talud; dan 6. Pengadaan perahu berlantai kaca (glass bottom boat) (Permenpar, 2018).

Ketentuan pembangunan sarana prasarana yang dibuat dalam peraturan ini salah satunya mengacu pada kapasitas dan kebutuhan pengguna (wisatawan) seperti menggunakan dimensi tubuh manusia (antropometri) untuk menentukan kenyamanan dan keamanan dalam menggunakan fasilitas. Antropometri merupakan salah satu bidang kajian dalam ergonomic. Data antropometri digunakan untuk berbagai keperluan, seperti desain stasiun kerja, fasilitas kerja, dan desain produk agar diperoleh ukuran-ukuran yang sesuai dan layak dengan dimensi anggota tubuh manusia yang akan menggunakannnya (Wignjosoebroto, 2008). Sehingga pemanfaatan ukuran antropometri, tidak hanya dalam merancang sarana prasarana serta fasilitas tetapi juga digunakan untuk merancang setiap produk yang dihasilkan di destinasi wisata antara lain produk hotel seperti desain hotel, desain kamar, desain 
perlengkapan hotel dan termasuk desain cinderamata.

Selain antropometri, pemanfaatan prinsip visual display dalam ergonomic di kawasan wisata merupakan hal yang penting. Misalnya penempatan gapura identitas, display atau rambu-rambu penunjuk arah, peta dan tanda-tanda tertentu untuk mencari lokasi di kawasan wisata. Penentuan jarak pandang, jenis huruf, ukuran karakter, pemilihan warna, penempatan akan meminimalkan kesalahan wisatawan dalam menerima informasi (Irwanti \& Mahadewi, 2019).

Saat ini bidang kajian ergonomic lebih bersifat komprehensif dan terintegrasi dalam bentuk pendekatan ergonomi total (PET) atau total ergonomic approach (Manuaba, 2005; 2006). PET menekankan pada pemberdayaan manusia dalam melakukan aktivitas sehari-hari sehingga mampu mengidentifikasi, membuat prioritas, berpikir positif dalam memperbaiki dan menjaga setiap kondisi kerja atau aktivitas yang dilakukan dengan baik tanpa menimbulkan hal-hal yang memperburuk keadaan (Adiatmika,dkk., 2007). Oleh karena itu PET menggunakan pendekatan sistemik, holistik, interdisipliner dan partisipasi (SHIP Approach) dan menggunakan intervensi berdasarkan kriteria teknis, ekonomis, ergonomis, sosial budaya, hemat energi dan tidak merusak lingkungan atau teknologi tepat guna (TTG) (Adiatmika, 2019).

\subsection{Ergonomi dalam pelayanan}

Dalam industry pelayanan, factor manusia (penyedia layanan) memegang peranan penting dalam menentukan tingkat kepuasan wisatawan. Kemampuan penyedia layanan untuk memberikan pelayanan secara cepat, tepat, efektif dan efisien tidak terlepas dari kondisi fisik, mental, lingkungan, beban kerja serta organisasi kerja penyedia layanan. Dalam beberapa penelitian menyebutkan bahwa pekerja di bidang perhotelan memiliki beban kerja tinggi yang berisiko meningkatkan kelelahan, keluhan otot dan stress kerja yang berdampak pada kualitas pelayanan yang diberikan. Sehingga prinsip ergonomic fitting task to the man harus diimplementasikan untuk menjaga keseimbangan antara tugas dengan kemampuan, kebolehan dan Batasan manusia dalam melakukan aktivitas kerjanya. Secara umum kemampuan, kebolehan dan batasan manusia ini ditentukan oleh beberapa factor, antara lain; umur, jenis kelamin, antropometri, status kesehatan dan gizi, kesegaran jasmani dan kemampuan kerja fisik (Manuaba, 1998). Apabila keseimbangan ini diperhitungkan maka pekerja akan dapat bekerja secara sehat, tanpa ada resiko sakit, cidera, maupun stress sehingga pelayanan yang diberikan akan optimal.

\subsection{Ergonomi dan teknologi informasi dan komunikasi}

Perkembangan teknologi saat ini memudahkan wisatawan untuk mengakses informasi perjalanan wisata yang akan dilakukan. Dalam kemkominfo (2019) tahapan penggunaan teknologi informasi dalam perjalanan ke destinasi wisata meliputi 3 hal, antara lain 1) Perencanaan (Planning): wisatawan membutuhkan perencanaan sebelum melakukan perjalanan ke destinasi wisata dengan melakukan pencarian informasi melalui web, page maupun media social yang kemudian dilanjutkan dengan melakukan online reservations dari reservasi tiket pesawat hingga penginapan, 2) dalam perjalanan di destinasi wisata, wisatawan menggunakan mobile phone untuk mengakses objek-objek wisata, kuliner, tempat atraksi wisata, dan sebagainya, 3) setelah melakukan perjalanan, wisatawan membagikan pengalaman melalui media social. Sehingga bisa disimpulkan bahwa pemanfaatan teknologi informasi di era digital ini sangat penting.

Untuk menunjang proses penyampaian informasi secara tepat dan 
akurat dibutuhkan penerapan prinsip display. Prinsip display yang digunakan di web, page maupun media social adalah bentuk implementasi ergonomic yang memudahkan wisatawan untuk mendapatkan informasi destinasi wisata yang akan dituju. Prinsip display memiliki fungsi untuk menghindari terjadinya kesalahan dalam informasi, mudah diingat, menarik untuk dibaca, menghindari kelelahan serta kebosanan terhadap konten-konten yang dimunculkan, dan sebagainya. Pengaturan huruf, jarak, layout, warna, animasi, dan konten adalah prinsip dasar penggunaan display.

\subsection{Ergonomi dalam aktivitas wisata}

Aktivitas wisata adalah kegiatan wisatawan yang dilakukan selama berada di destinasi wisata. Beragam aktivitas wisata yang dilakukan oleh wisatawan antara lain cycling, tracking, jogging, walking in the rice field, rafting dan sebagainya. Dalam melakukan aktivitas wisata, selalu diupayakan agar wisatawan tetap sehat, aman dan nyaman.

Penerapan prinsip-prinsip ergonomic dalam menciptakan keamanan dan kenyamanan dalam melakukan aktivitas wisata sangat penting, dalam hal ini perlu diperhatikan; 1) jenis aktivitas wisata yang dilakukan (apakah dalam kategori aktivitas dengan beban berat, sedang atau ringan), 2) alat yang digunakan apakah sudah memenuhi kaidah aman dan nyaman, serta 3) pemanfaatan waktu dalam melakukan aktivitas tidak melebihi kapasitas fisik dan psikis wisatawan. Misalnya sebelum melakukan aktivitas cycling maupun tracking, wisatawan yang ikut dalam kegiatan ini harus memenuhi ketentuan 1) kesesuaian antara kapasitas dengan aktivitas wisata dilihat dari umur, jenis kelamin, kesegaran jasmani dan kapasitas fisik, 2) penentuan jarak tempuh dan 3) waktu istirahat, istirahat dibutuhkan ketika beban fisik meningkat yang ditandai dengan meningkatnya denyut nadi.

Denyut nadi merupakan salah satu tolak ukur menentukan beban fisik dalam melakukan aktivitas, karena cara tersebut dapat memberikan indikasi tentang aktivitas dalam sel, jika aktivitas tubuh mengalami peningkatan beban dari biasanya, maka denyut nadi juga meningkat (Grandjean \& Kroemer, 2000). Terkait dengan hal tersebut, ada beberapa kategori beban aktivitas seperti pada Tabel 1.

Tabel 1 : Kategori Beban aktivitas Berdasarkan Denyut Nadi Kerja [Sumber : Grandjean \& Kroemer, 2000]

\begin{tabular}{ccl}
\hline No & Rentang Denyut Nadi & Kategori Beban Aktivitas \\
\hline 1 & $60-75$ & Sangat Ringan (istirahat) \\
2 & $75-100$ & Ringan \\
3 & $100-125$ & Sedang \\
4 & $125-150$ & Berat \\
5 & $150-175$ & Sangat Berat \\
6 & $175<$ & Ekstrim \\
\hline
\end{tabular}

Cara menghitung denyut nadi secara manual dengan teknik palpasi dapat dilakukan dengan cara: (a) denyut nadi dihitung selama 6 detik; hasilnya dikalikan 10; (b) denyut nadi dihitung selama 10 detik; hasilnya dikalikan 6; (c) denyut nadi dihitung selama 15 detik; hasilnya dikalikan 4; dan (d) denyut nadi dihitung selama 30 detik; hasilnya dikalikan 2. Sehingga ketika wisatawan sudah berada pada kategori beban aktivitas berat ketika melakukan aktivitas cycling, tracking maupun aktivitas fisik lainnya, maka wisatawan dapat beristirahat pada rest area di rute- 
rute tertentu yang sudah disiapkan secara ergonomis.

\subsection{Kondisi lingkungan destinasi wisata yang ergonomis}

Ergonomi memegang peranan penting untuk menentukan kualitas lingkungan. Standar ergonomi untuk kondisi lingkungan yang nyaman, aman dan sehat dari paparan suhu, kelembaban, pencahayaan, tingkat kebisingan, tingkat polusi udara, polusi bau, dan polusi air dilakukan secara terukur. Bila ini berpengaruh maka peran ergonomic akan tampak nyata (Irwanti \& Mahadewi, 2019).

\subsection{Implementasi Nilai Ergonomi dalam Pariwisata yang Berkelanjutan}

Pariwisata dijadikan sebagai sektor unggulan dalam pembangunan nasional setiap negara dan menjadi lokomotif pembangunan sektor lainnya sudah tidak dapat disangkal lagi (UNWTO, 2018). Untuk meminimalisasi dampak negatif pembangunan sektor pariwisata, maka perlu dilakukan pembangunan pariwisata yang berkelanjutan. Ada 17 sustainable development goals (SDGs) yang dapat digunakan untuk menerapkan pembangunan pariwisata yang berkelanjutan, seperti pada Gambar 1 berikut:

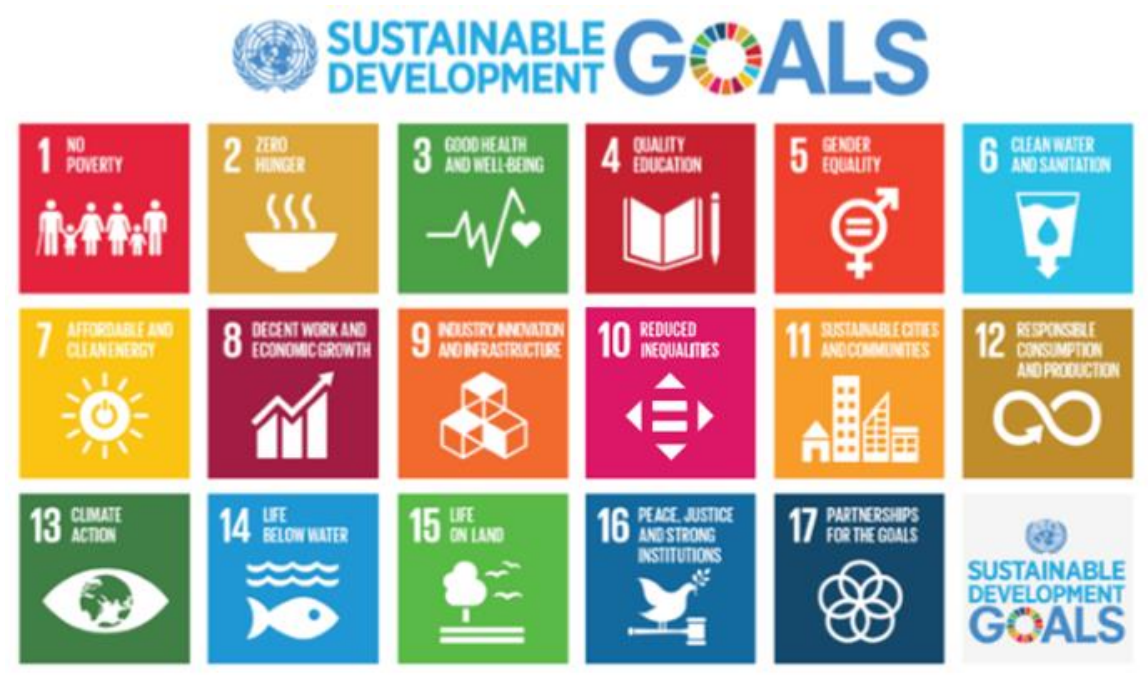

Dari 17 (tujuh belas) tujuan dalam Gambar 1 diatas; bagian ketiga terkait kesehatan dan kehidupan lebih baik menjadi sorotan perlunya implementasi nilai-nilai ergonomis dalam setiap pembangunan. Pada tujuan yang ketiga ini adalah untukmemastikan kehidupan masyarakat yang sehat dan sejahtera pada setiap tingkatan usia (Ensure healthy lives and promote well-being for all at all ages). Penyediaan fasilitas dan produk yang sesuai dengan kebutuhan dan keinginan wisatawan telah menciptakan sarana dan prasarana yang bersih dan sehat. Lingkungan alam juga telah dibangun sedemikian rupa sehingga memenuhi unsur estetika, sanitasi dan preservasi atau konservasi. Biasanya orang dan lingkungan fisik yang terkait langsung dengan penyediaan produk untuk wisatawan sudah memenuhi unsur kesehatan dan sanitasi serta pemeliharaan lingkungan. Namun, fasilitas atau kebiasaan sehari-hari belum tentu sudah memenuhi unsur kesehatan dan pemeliharaan lingkungan ini. Oleh karenanya, perubahan yang perlu dikembangkan adalah perubahan gaya hidup pada setiap sendi kehidupan, tidak hanya pada saat bekerja untuk memenuhi kebutuhan wisatawan. Sebagai contoh, area untuk wisatawan 
dibuat sangat bersih tetapi area yang digunakan sehari-hari yang tidak terlihat tamu masih kotor. Perlu perubahan pola pikir yang dibudayakan dalam kehidupan sehari-hari.

Selain bagian ketiga pada gambar SDG's tersebut diatas; tujuan ketujuh juga menjadi bagian yang perlu diperhatikan. Bagian ketujuh ini adalah meyakinkan akses energi yang terjangkau, terpercaya, dan keberlanjutan untuk masyarakat lokal (Ensure access to affordable, reliable, sustainable and modern energy for all). Hal sama untuk pemakaian energi, hotel harus dikelola secara efisien, sehingga tidak mengganggu pasokan energi untuk masyarakat lokal. Pasokan energi ini agar terjangkau dan berkelanjutan. Dengan pengeloaan energi yang efesien dan ramah lingkungan maka akan dapat meningkatkan citra destinasi sebagai daerah yang ramah lingkungan dan jaminan energi untuk para pengelola industri hospitaliti dan lainnya.

Setelah membahas bagan ketiga dan ketujuh diatas; pada bagian kesembilan adalah membangun kemandirian infrastruktur untuk mempromosikan industri yang bekelanjutan dan meningkatkan inovasi (Build resilient infrastructure, promote sustainable industrialization and foster innovation). Pembangunan infrastruktur yang ergonimis dapat menjadi dasar dalam setiap pembangunan destinasi. DAlam aspek pendukung lainnya, pembangunan pariwisata harus berbasis budaya lokal untuk menjamin keberlanjutan keunikan dan preservasi budaya lokal. Infrastruktur yang bagus untuk masyarakat umum dan wisatawan akan dapat meningkatkan kesejahteraan masyarakat lokal. Esensi dari pembangunan kepariwisataan adalah meningkatkan kesejahteraan masyarakat lokal sehingga mereka dapat memberikan produk dan layanan yang berkesan dan memuaskan yang bebasis keunikan dan budaya/lingkungan alam setempat.
Keberhasilan destinasi dengan memperhatikan nilai-nilai ergonomi yang sudah terimplementasi sesuai tujuan 3 , tujuan 7 , tujuan 9; maka tujuan kesebelas juga menajdi penting diperhatikan. Tujuan kesebelas adalah membuat kota/desa inklusif, aman, tangguh dan berkelanjutan (Make cities inclusive, safe, resilient and sustainable). Esensi pariwisata adalah keunikan, kebermanfaatan dan kenyamanan yang dimiliki oleh penduduk lokal yang kemudian menarik untuk dikunjungi oleh wisatawan. Jadi obyek, daya Tarik, produk, atau layanan adalah gaya hidup masyarakat setempat yang kemudian dapat dinikmati oleh wisatawan. Bila demikian halnya, maka keamanan, inlusivitas, ketangguhan, dan keberlanjutan tidak dibuat-buat, melainkan nilai yang dimiliki dan dijalankan oleh masyarakat setempat.

Nilai ergonomic dapat dikaitkan dengan tujuan keduabelas pada model gambar SDG's diatas. Tujuna keduabelas adalah menjamin pola konsumsi dan produksi yang berkelanjutan (Ensure sustainable consumption and production patterns). Perlu dibangun pola produksi dan konsumsi yang ramah lingkungan dan aman untuk penduduk lokal. Pengelolaan sumberdaya yang efisien menjamin keberlajutan dengan tidak mengekslpoitasi sumberdaya secara berlebihan dengan pengorbankan kepentingan generasi mendatang. Pembangun pariwisata disesuaikan dengan kapasitas lingkungan dan masyarakat setempat sehingga ada keharmonisan antara penduduk dan antara penduduk dengan lingkungan serta antara wisatawan dengan penduduk.

Dampak penerapan nilai ergonomi dalam pariwisata, terlihat pada tujuan keenambelas dari gambar SDG's diatas. Tujuan keenambelas adalah mempromosikan keadilan, kedamaian, dan masyarakat yang inklusif (Promote just, peaceful and inclusive societies). Pembangunan pariwisata diarahkan untuk mempromosikan keadilan melalui 
distribusi pendapatan yang berkeadilan untuk kesejahteraan masyarakat lokal. Dengan kualitas hidup yang lebih baik maka masyarakat lokal akan dapat memberikan pelayanan yang lebih berkualitas sehingga akan tercipta destinasi yang damai dan berkelanjutan. Interaksi masyarakat lokal dengan wisatawan akan dapat meningkatkan pemahaman antar negara sehingga perdamaian dunia dapat tercipta. Semua ini bisa dicapai jika fokus pembangunan pariwisata adalah membangun individu yang penuh cinta dan perdamaian sehingga kedamaian destinasi sebagai konsekwensi dari kedamaian individu baik masyarakat lokal maupun wisatawan akan dapat tercipta.

Sampai pada terakhir yakni tujuan ketujuhbelas adalah merevitalisasi hubungan global untuk pembangunan yang berkelanjutan (Revitalize the global partnership for sustainable development). Pembangunan pariwisata tidak membangun dominasi kelompok atau negara namun membangun kesetaraan untuk keharmonisan. Oleh karena itu, setiap pemangku kepentingan harus memahami peran dan peranannya untuk membangun sektor pariwisata yang berkelanjutan. Pemerintah sebagai regulator hanya memiliki kepentingan pembangunan pariwisata yang berkelanjutan, bukan atas dorongan peningkatan pendapatan atau membela kelompok atau golongan tertentu. Semua aktivitas pembangunan kepariwisataan diarahkan untuk kesejahteraan masyarakat dan wisatawan dalam jangka panjang dan berkelanjutan.

Tujuhbelas tujuan pembangunan pariwisata yang berkelanjutan pada penerapannya dengan pendekatan nilainilai ergonomis sangat relevan untuk mendukung pembangunan yang pada akhirnya mereka dapat berperan dalam pembangunan kepariwisataan. Infrastruktur dan pola kerja yang ergonomis serta yang memadai akan memungkinkan destinasi dan para pekerjanya bekerja dan meningkatkan pendapatanya sehingga ada peningkatan kualitas hidup. Dengan kesejahteraan masyarakat lokal maka mereka dapat berkonsentrasi untuk menjaga kesehatan dan meningkatkan pelayanan untuk wisatawan.

\section{KESIMPULAN}

Berdasarkan uraian tersebut, dari sudut pandang ergonomi dapat disimpulkan bahwa Daerah tujuan wisata ergonomis adalah kawasan wisata yang menyediakan aktivitas, sarana prasarana, fasilitas dan pelayanan yang aman, nyaman, sehat, efektif dan efisien dengan mempertimbangkan kemampuan, kebolehan dan batasan stakeholder pariwisata untuk mendapatkan kualitas hidup yang lebih baik, bahagia dan berkelanjutan.

Dengan implementasi nilai-nilai ergonomis pada model Sustainable Development Goals (SDG's); dapat menjadi bagian yang digunakan untuk pedoman pembangunan pariwisata yang berkualitas, menciptakan masyarakat dan wisatawan bahagia serta secara keseluruhan terwujudnya pariwisata yang berkelanjutan.

\section{DAFTAR PUSTAKA}

Adiatmika, 2019. Implementasi Ergonomi untuk Wisata dan Wisatawan Berkualitas menuju wisata Berkelanjutan. Seminar Regional "Ergonomics Tourism for Millenial Hospitalitier". Badung, 25 April 2019

Adiatmika, I.P.G., Manuaba, A., Adiputra, N., Sutjana, D. P. (2007). Perbaikan Kondisi Kerja Dengan Pendekatan Ergonomi Total Menurunkan Keluhan Muskuloskeletal Dan Kelelahan Serta Meningkatkan Produktivitas Dan Penghasilan Perajin Pengecatan Logam Di KediriTabanan. Indonesian Jurnal of Biomedical Sciences. Vol 1(3). Des 2007

Grandjean, E., Kroemer, 2000. Fitting the Task to the Human. A textbook of 
Mahadewi, Irwanti

Occupational Ergonomics. 5th edition. Piladelphie : Taylor \& Francis Irwanti, N.K.D. \& Mahadewi N.M.E. (2019). Ergonomic Destination, a Quality Tourism Identity. LAP Lambert Academic Publishing

Kemkominfo (Kementerian komunikasi dan informasi RI), 2019. Pentingnya Teknologi Dalam Sector Pariwisata. https://aptika.kominfo.go.id/2019/0 4/pentingnya-teknologi-dalamsektor-pariwisata/. diakses 7 September 2020.

Manuaba, A. 2003. 'Organisasi Kerja, Ergonomi dan Produktivitas'. Seminar Nasional Ergonomi, Jakarta, 9 - 10 April.

Manuaba, A. 2006. Macro Ergonomics Approach On Work Organizations With Special Reference To The Utilization Of Total Ergonomic SHIP Approach To Obtain Humane, Competitive And Sustainable Work System And Products. Proceeding Seminar Nasional Ergonomi. Surabaya, 21-22 November 2006.

Manuaba, A., 2005. Pendekatan Holistik dalam Aplikasi Ergonomi. Sosial \& Humaniora. 0kt;01(01):1-13.

Permenpar, 2018. Peraturan Menteri Pariwisata Republik Indonesia tentang Dana Alokasi Khusus Pembangunan Pariwisata. http://www.djpk.kemenkeu.go.id/w pcontent/uploads/2018/08/PERMEN PAR-NOMOR-3-TAHUN-2018-

TENTANG-DAK-FISIK-BIDANGPARIWISATA. diakses 7 September 2020

Tarwaka, 2010. Ergonomi Industri. Surakarta : HARAPAN PRESS.

United Nations (UN). 2018. The Sustainable Development Goals Report. New York 